\title{
Jo sóc armat. Reivindicant la identitat cristiana i local ${ }^{1}$
}

\author{
Jordi Suñé Morales \\ Màster en Antropologia Urbana, Universitat Rovira i Virgili \\ jsune4@xtec.cat
}

Resumen: En este artículo nos proponemos analizar las motivaciones de un grupo de participantes de las procesiones de Semana Santa conocidos como los "armats" de una población de la costa catalana. Esta cofradía está formada por un grupo de unos treinta hombres. Van caracterizados com si fueran soldados romanos y acompañan a la figura de Jesucristo en las procesiones que rememoran su muerte. La identidad fuerte del grupo, conseguida a partir de un funcionamiento ritualizado, consolida una práctica de origen religioso en un contexto de reencantamiento de la vida, de multiplicidad de prácticas religiosas, del uso moderno de la tradición y de la reivindicación de la localidad en un momento de cambios fruto de la globalización.

Palabras clave: identidad, ritos, tradición, Semana Santa.

Abstract: This article analyzes the motivations of a group of participants in the Easter Week processions known as "armats" in a town on the Catalan coast. This brotherhood consists of about thirty men. They dress up as Roman soldiers and accompany the figure of Jesus Christ in the processions that recall his death. The strong identity of the group, brought about by ritualized performance, reinforces a faith-based practice in a context of re-enchantment of life, a multiplicity of religious practices, the modern use of tradition and the demand for local recognition at a time of change resulting from globalization.

Keywords: identity, ritual, tradition, Easter.

\footnotetext{
1. Aquest treball ha estat possible gràcies a la tutorització del professor de la URV Jaume Vallverdú realitzada en el marc de l'assignatura Treball de Fi de Màster, del màster d’Antropologia Urbana. El meu més sincer agraïment.
} 


\section{Introducció}

Què hi fa una colla d'homes disfressats de soldats romans desfilant un dia l'any per aquests carrers plens de blocs de pisos i de càmeres digitals apuntant a les seves armadures? Què els motiva a sortir així? En un context d'identitats líquides, com és possible una cohesió tan forta de grup? Quines són les estratègies, conscients o inconscients, emprades per l'entitat per crear vincles forts? En tot plegat, quin paper hi juga la reivindicació de la localitat en un context de globalització?

El pas dels armats, la colla d'homes vestits de romans que acompanyen la imatge de Jesucrist crucificat a moltes processons de Setmana Santa, és un dels atractius dels actes que rememoren la passió i la mort del fill del Déu dels cristians. Els armats, juntament amb altres elements, reviuen uns fets bistòrics $i$ mitics transcendentals per als fidels d'aquesta religió. Representen l'exèrcit romà, el que acatava les ordres de Ponç Pilat — el governador de la província romana de Judea entre els anys 26 i 36-, el que vigilava que l'ordre establert continués intacte. Amb ells, amb els armats, amb un grup d'un municipi de la costa tarragonina, vaig compartir hores de treball de camp, sortides, àpats, reunions $i$ entrevistes, al llarg del 2010 i una part del 2011, per tal de conèixer de prop la seva realitat. ${ }^{2}$

El primer que crida l'atenció dels armats és que enfront del procés de desencantament del món - el procés de racionalització de la realitat divina i humana característic de les societats modernes descrit per Max Weber-, aquesta colla d'homes els situem, més aviat, en el procés de reencantament - el procés de crisi de les institucions religioses, com l'Església, però amb una multiplicació de creences i pràctiques com a conseqüència de la modernitat avançada, descrit per Manuela Cantón (2001) —. Ens trobem davant de pràctiques d'estètica barroca, on les imatges sagrades prenen una importància cabdal, on els practicants viuen a la seva manera el sentiment religiós, però ho fan d'una manera sentida i pública. És a dir, no ens trobem davant d’una societat tradicional en

2. Es tracta d'un grup que manté una activitat social al llarg de l'any però que aboca els esforços durant els dies de Setmana Santa. Concretament, les seves activitats públiques són les següents: presentació de l'opuscle-programa d'actes de la Setmana Santa el Divendres de Dolors, ofrena del Ciri Pasqual el Diumenge de Rams, processó del Dolor de Dimecres Sant a Tarragona, viacrucis del Divendres Sant i processó al vespre. I, finalment, cantada de caramelles el Diumenge de Pasqua. A les processons i al viacrucis, els armats desfilen com si fossin soldats romans, vestits com a tals, seguint les ordres d'un capità i encapçalats per un estendard. 
què la religió juga un paper central. Tanmateix, sí que hi ha un apropament a l'Església en moments puntuals que, a més, són d'un gran sentit espiritual. Com ha descrit l'antropòleg Pedro García (2010: 37), la modernitat no es caracteritza per l'absència d'allò sagrat, sinó per la seva pluralitat. És aquesta pràctica una mostra d'aquesta pluralitat?

L'estudi de l'evolució del grup, des de la seva represa el 1962 fins ara, ens permet adonar-nos que en els darrers anys s'ha produït un apropament a l'Església, una participació cada cop més compromesa amb el conjunt de la Setmana Santa, una institucionalització de la seva participació — es redacten uns estatuts, es crea una junta directiva, etc.- i una introducció constant de símbols religiosos en els seus actes. No es tracta tan sols de la recuperació d'unes tradicions. Hi ha alguna cosa més. La tradició era ben senzilla i humil i tot sovint quedava al marge de la jerarquia eclesiàstica. Ens trobem davant d'un procés de reencantament explícit. Hi ha una ostentació volguda dels símbols religiosos fora de les quatre parets del temple.

Amb la crisi que hi ha del tema religiós, jo crec que està molt sana [la Setmana Santa torrenca]. Té bona... La gent s'aferra molt al tema d'aquests actes que hi ha. Potser anar a missa cada diumenge no. Però quan hi ha un acte de missa, és igual si és una processó, si és una missa gospel, o una missa rociera, és igual; vull dir, la gent, a aquestes coses puntuals, a allò sí que hi va. La processó va bé. Calculem que són 500 persones que hi participen. (Membre dels armats.) ${ }^{3}$ A més a més, aquesta evolució va marcada també per una voluntat de millorar constantment els detalls i la posada en escena. El seu objectiu no solament és oferir un espectacle estètic rellevant i sorprendre als espectadors. Es tracta també de diferenciar-se dels altres municipis que tenen armats. I per fer-ho no han dubtat a introduir elements simbòlics a les robes $i$ a les imatges que recordin la localitat i assajar amb tanta previsió com sigui possible. Els recursos abocats són els necessaris per lluir amb elegància. Els seus relats són plens de referències a la joia de portar el nom del seu poble ben amunt, amb una dignitat que sorprèn.

\footnotetext{
3. Les entrevistes es van realitzar a les cases dels informants. Es van enregistrar en vídeo i es van analitzar posteriorment. La primera es va fer el 6 de juny del $2010 \mathrm{i}$ la darrera, el 3 de maig del 2011. Es van entrevistar 27 persones, 9 de les quals de manera individual, 6 per parelles i la resta en grups.
} 


\section{2 . Identitats}

Els canvis produïts al si d'aquest grup d'armats és una resposta totalment moderna. No ens trobem davant d'un grup tradicional que viu el calendari litúrgic i festiu a l'antiga. La seva evolució ens parla d'uns canvis que persegueixen uns objectius que sallunyen de la tradició. Més aviat, la tradició és reinterpretada per justificar els canvis. Els armats han fet gran la Setmana Santa, han fet apropar molta gent a l'Església, han revalorat moltes de les pràctiques que estaven en vies de desaparició $i$ han tret l'Església al carrer, amb una posada en escena digna i seriosa. D'altra banda, l'Església — la tradició — ha donat legitimitat als armats per protagonitzar la Setmana Santa, aquest gran acte dramatúrgic contemplat per centenars de persones. L'Església ha cedit espais on desenvolupar les seves activitats ordinàries i ha facilitat tota una sèrie de ritus que els armats necessiten per al desenvolupament de les seves activitats. En aquest sentit, podem esmentar la recollida de la creu a les Monges, la parada militar que es fa a les escales de l'altar, la portada del ciri o l'encapçalament de la processó.

Altres treballs han analitzat com la sociabilitat confrare pot actuar de mecanisme de retradicionalització selectiva de la vida contemporània, i es converteix en un mecanisme de reencantament. Malgrat tot, la tradició ja no estructura les nostres vides (García, 2010: 157); forma part de les nostres tries i de la nostra identitat múltiple. Lús de la tradició dels armats en un context de canvi permanent, per crear un espai de sociabilitat amb una identitat de grup forta, comporta un procés de reencantament d'una colla d'homes que en cas contrari podrien estar ben lluny de l'Església. Els rituals tenen lloc al voltant de les celebracions religioses $i$ tenen un caràcter retrospectiu i sagrat.

Tal com indica Zygmunt Bauman (2003), la globalització és un procés que no es pot aturar i que produeix influències profundes. Ara bé, les seves conseqüències no tenen uns efectes unitaris, tal com es podia preveure. D'una banda, els negocis i els fluxos d'informació esdevenen planetaris. Però, de l'altra, es posa en marxa el procés "localitzador", de fixació en l'espai. Alhora, l'esmentada fixació a l'espai implica que moltes vegades es reafirmin identitats, s'exaltin localismes i es veneri certa tradició. El grup estudiat reivindica la localitat en un context de globalització tot cercant diferenciar-se. I, tal com indicava LéviStrauss (1979), la diferència cultural emergeix, precisament, quan hi ha contacte cultural. És llavors quan hi ha consciència de la diferència. Aquest fet és 
més habitual en un context d"'homogenización y hegemonía de la civilización" com l'actual més que no pas amb l'aillament cultural (Rodríguez, 2004). Ara el contacte cultural és més gran que mai i la diferència emergeix. Davant d'aquest contacte i el procés d'homogeneïtzació, aquests homes es rebel.len emfatitzant els trets particulars i, fins i tot, creant-ne de nous. És allò que defensava el noruec Frederik Barth (1976) sobre la identitat: no es crea a partir dels trets culturals, sinó que és la voluntat de la diferència la que crea la identitat. Se cerquen trets distintius per tal de crear una identitat diferenciada.

La globalització ha comportat un canvi en la definició de la identitat. El territori delimitat ja no és suficient per marcar una identitat. Davant les migracions, els grups humans accentuen els seus trets particulars per sentir-se segurs o per crear comunitat lluny de la terra originària. ${ }^{4} \mathrm{El}$ cas estudiat es correspon amb el primer supòsit. Al grup no hi ha barreja d'orígens, tret d'algun cas excepcional. Les creences religioses no són suficients per unir persones vingudes d'arreu del món que comparteixen un mateix territori. Cal una cosa més: la tradició de la localitat, el sentiment de pertinença al lloc. És per això que moltes cultures populars no desapareixen i més aviat es transformen (García Canclini, 1990: 200). Aquesta aposta té el suport de l'administració local, que aprofita el potencial turístic de l'espectacle al carrer.

Malgrat tot, i tal com apunta Appadurai, "la tarea de producir lo local (en tanto una determinada estructura de sentimientos, propiedad de la vida social e ideología de una comunidad situada) es, cada vez más, una verdadera lucha" (Appadurai, 2001: 197). I en aquesta lluita s'emmarca el treball de l'entitat.

L'antropòleg Marc Augé (2008: 41) també s'ha fet ressò d'aquesta paradoxa: "en el momento mismo en que la unidad del espacio terrestre se vuelve pensable $y$ en el que se refuerzan las grandes redes multinacionales, se amplifica el clamor de los particularismos”. Per a l'antropòleg Joan Frigolé (2006), parlant de patrimoni, la reelaboració de la localitat és una resposta a la globalització. La localitat i la globalització són interdependents. Tal com apunta l’antropòloga Josepa Cucó (2004: 174), el fenomen d'inscriure’s en un àmbit geogràfic i identificar-s' hi té a veure amb la desaparició de les identitats tradicionals.

\footnotetext{
4. La variació interanual d'immigrants arribats a Catalunya l'any 2004 va ser d'un $169,4 \%$ (Idescat). Catalunya té un $15,72 \%$ d'immigrants (2011), la xifra més alta de l'Estat — l'any 2000 representava el 4,1\%—. Al poble estudiat, el 18,81\% de ciutadans són originaris de fora l'Estat (2011).
} 


\section{Crear el sentiment de pertinença}

S'imposa el model de "sociabilitat postmoderna" que permet donar sortida a la nostra vida individualista $i$, alhora, poder satisfer la nostra necessitat gregària (Lacroix, 2005). I en aquest context reneix el sentiment d'identitat que dóna "sentido y cobijo a la vez, crea una práctica cómplice, un lenguaje común, un mundo propio desde el que se puede vivir con más tranquilidad el mundo de ajenidades" (Castells, 2005). Però és una identitat que l'individu assumeix com una més de les que té.

Berger i Luckmann (1997) han analitzat com les societats modernes pateixen crisis latents de sentit. Les institucions intermèdies poden contribuir a la negociació i a l'objectivació social del sentit. Així, pot facilitar que els individus no se sentin "como completos extraños en el mundo moderno". Perquè les entitats locals esdevinguin institucions intermèdies han d'actuar com a mediadores entre les grans institucions de la societat $i$ els individus en les seves comunitats de vida. En aquest sentit, els autors esmentats refermen la importància de l'Església encara avui. Perquè es tracta d'una institució especialitzada a produir i transmetre sentit. Ja no és l'única. El paper de l'Església s'ha reduït a la d'una institució secundària que assumeix un rol privat. Pot, però, jugar un paper important donant sentit als seus membres i fent de pont entre la vida privada i la participació en institucions socials.

En el cas estudiat, el treball de la cohesió de grup i del sentiment de pertinença es fa a partir dels dos eixos esmentats: la religió i la localitat. La "dimensió cultural”, en termes de Clifford Geertz (1990ः 87-117), inclou un esquema històricament transmès de significacions representades en símbols, a través dels quals es comuniquen i es transmeten els coneixements i les actituds. Per aconseguir una cohesió de grup, calen elements que identifiquin i que comuniquin els seus membres. És aquí on podem situar la funció dels símbols i dels ritus.

Tal com defensava Durkheim (2003), els ritus tenen una funció de cohesió social. Els rituals de grup tenen un caràcter sagrat i retrospectiu, on l'individu rememora celebracions precedents i pren consciència de la col.lectivitat. La vivència d'aquesta mística produeix uns efectes entre els membres. Les activitats religioses provoquen estats d'ànim de diferents intensitats i motivacions. És amb el ritu religiós on es generen concepcions veritables, on es referma l'autoritat religiosa, les motivacions i els estats anímics. Durkheim parla de l'efer- 
vescència, de l'exaltació de les emocions, de l'emotivitat del grup. En aquest sentit, els símbols concentren tots aquests poders d'evocació (Vallverdú, 2008: 60-61).

L'entitat és plena de rituals. Aquest fet facilita l'estabilitat, la reproducció i el control del grup. Tothom que entra, amb poc temps, sap què ha de fer i com actuar. Però, a més a més, els ritus tenen un objectiu clar de cohesió del grup, treballant especialment el sentiment de pertinença. El poder de suggestió dels ritus és tal que fins i tot un no creient pot arribar a tenir els seus dubtes en el moment culminant de les cerimònies:

Aquella tradició que a vegades et fa... Com santa Rosalia ${ }^{5}$ i aquestes coses, no? Que no tenim afinitat a l'Església i aquestes coses. Però quan fas d'armat hi ha aquell moment que dius... Hi ha un moment que penses... Hòstia! Hi ha moments que penses: però si tot l'any no practico, no ho faig, no sé què. A mi em passa molt per la festa major, quan entro a veure els pilars dintre de l'església i el Raül toca l'ofertori, no? I em passa aquella sensació de dir: "Que hi crec amb això ara? No?" En aquell moment hi creus! A mi em passa en aquell moment. Hi ha un moment amb els armats que és quan ens posem dalt de l'altar, el divendres, que tothom ve a besar el Crist... bueno! Jo vaig a besar el Crist com... bueno! I jo no hi vaig mai a besar el Crist, però en aquell moment et converteixes. Hi ha un moment que et fa pensar: "Què passa aquí?" (Membre dels armats.)

Per a Victor Turner, els rituals formen part dels processos socials que sesdevenen en una comunitat. Els ritus poden tenir dues funcions diferents. D'una banda, poden corregir desviacions de conductes establertes en els costums. De l'altra, poden prevenir conflictes establint rituals periòdics i rituals per a les crisis vitals. En aquest sentit, podem esmentar el discurs del capità manaies abans de les sortides o els ritus de pas. ${ }^{6}$

Els ritus van ser definits per Arnold van Gennep en una obra publicada el 1909 (Les rites de passage). Posteriorment, Victor Turner (1988: 101-136) va reprendre el tema. Els ritus de pas tenen un caràcter simbòlic. Acompanyen tot canvi de lloc, estat, posició social i edat. Els ritus de pas tenen tres fases (pre-

5. Festa major del municipi celebrada cada 4 de setembre, combinant actes de caire religiós i altres de populars com els balls de societat.

6. El capità manaies és l'autoritat carismàtica dels armats. Porta una espasa en comptes d'una llança. Dirigeix el pas de la tropa i camina amunt i avall controlant tots els detalls. 
liminar, liminar i postliminar). La primera respon a una conducta simbòlica que escenifica la separació d'un punt fix de l'estructura social per ascendir a una etapa superior. La segona etapa es correspon amb el moment que el subjecte es troba en una fase intermèdia, ambigua. Finalment, la tercera fase suposa la reincorporació a la nova situació social i a l'estabilitat. El seu nou rol està definit i el seu comportament és previsible segons el context cultural.

En la vida de l'entitat estudiada, la primera sortida - la primera processó fent d'armat - representa el canvi d'estatus, el pas d'una situació liminar a l'estabilitat de ser un membre de ple dret, de formar part de l'estructura. S'acaba d'aquesta manera la situació provisional, transitòria, de punt mort, indefinida de ser armat però no ser titular o de ser membre de l'entitat però no sortir a les processons.

Ostres, imposa molt la gent, o sigui, els homes, no? Allò, perquè clar, tu ets jovenet, jo tenia potser 16 o 17 anys quan entrava, i clar, pues te trobes tota la tropa, que són aquells homes, no? Aquella ferum, també, a home que fa quan ens canviem els dies d'anar a processó. La serietat, aquest ambient més serio, per dir-ho d'alguna manera. Clar, venies de la joventut, venies de la infantesa i és com que te poses en contacte, no?, amb una altra generació, vius més de prop aquesta generació i tu també fas com un de... com se diu? Un pas de cicle. (Membre dels armats.)

Entre els recursos simbòlics, els més importants són aquells que inciten els seus membres a participar de manera convençuda en les activitats de l'entitat, que són aquells que busquen el compromís. Es tracta d'un compromís que fa superar les pors, que implica emocions, gratificació malgrat els sacrificis.

\section{La consciència col-lectiva i la fraternitat}

Per a Durkheim, la "consciència colllectiva" comporta l'existència de creences i sentiments. En les societats "tradicionals" és la religió qui recull la consciència col-lectiva. El càstig té la funció de protegir i reafirmar la consciència colllectiva. Com més es desenvolupa una societat, menys s'empra el dret repressiu i més el restitutiu.

La "solidaritat orgànica" de les societats modernes permet mantenir la cohesió social. Aquesta solidaritat no es basa en unes creences religioses — situació 
típica de la solidaritat mecànica de les "societats tradicionals" - , sinó que és la interdependència funcional resultant de la divisió del treball el que la fa possible. Malgrat que la "consciència colllectiva" decreix amb el desenvolupament de les societats, es manté un mínim de creences i sentiments comuns que permeten que existeixin "dissidències individuals".

Però aquestes "dissidències individuals" es generalitzen en un context on les solidaritats es difuminen (Giddens, 1998). En un món "posttradicional", en termes del sociòleg Anthony Giddens, on el temps i l'espai s'han transformat i la vida social s'ha alliberat de la dependència i dels preceptes i pràctiques establertes (Giddens, 1997: 33), les pràctiques religioses tenen un component hedonista, de plaer immediat. Les bones conductes no poden esperar la recompensa en la promesa d'una altra vida millor. Per tant, hem de considerar la tria de les activitats de lleure com una elecció lliure de l'individu, tenint en compte el context social i la voluntat de gaudi.

Ser armat és un sentiment difícil d'explicar. Però és facil adonar-se que té un component de plaer. Un armat aclareix que, malgrat que les processons són cansades físicament, s'ho passa molt bé. És un espai que ha esdevingut un lloc de trobada de la família, que també s'hi ha anat involucrant amb els anys. És un projecte que l'engresca i que l'evadeix dels problemes diaris:

Allà pots desenvolupar una altra àrea teva, personal, que t'ho passes bé, que tocupa però no et preocupa. I fent d'armat doncs m'ho passo molt bé. Em dóna un toc de reflexió personal. Hi ha alguns moments introspectius també molt bonics, que magraden. I potser també em sento molt bé amb aquell ordre. Amb aquell ordre però acompanyat de tots, que saps que no ets tu sol. És aquella comunió amb tota la gent, que estem seriosos allà plantats. [... A Amb els dinars, els sopars, els esmorzars t'ho passes molt bé. I a més a més, jo que no tinc antecedents històrics familiars aquí al poble tassabentes de moltes coses d'aquí i t'ho passes fenomenal. És molt bonic. I per a mi, tota aquesta gent, són una miqueta els meus avantpassats d'aquí al poble que no tinc. I et fa ser una miqueta més d'aquí sense haver-ho sigut anteriorment. (Membre dels armats.)

Ser armat és una qüestió important per a les persones que en formen part. Normalment, ho són durant molts anys. Així, per exemple, n’hi ha que porten uns trenta-cinc anys. "Som una família, la família de la Setmana Santa, perquè passes moltes hores junts", comenta un dels seus membres. El mateix afirma 
"qui entra es queda. Hi ha bon ambient". "Els armats t'atrapen més pel que la gent no veu que pel que es veu, quan et vesteixes, les conyes, aixeca't d'hora, esmorzar, els sopars, la primera reunió que fem ja anem a sopar al Fran...", rebla un altre dels informants.

Malgrat la serietat dels armats, els moments divertits són a l'ordre del dia. "Lambient de després de les actuacions, els sopars, els esmorzars, la juerga que es viu" "Eren unes conyes que, si ets molt petit, no les entenies". "Són conyes d'homes grans, eren bromes d'homes grans, allà et fas gran, et curteixes".

Els àpats que els armats realitzen estan fixats en les mateixes dates cada any - el sopar de després de l'assemblea anual, l'esmorzar de Divendres Sant a Baix a Mar a casa d'un soci, el sopar de Divendres Sant, el sopar de gala, etc.- . Els àpats colllectius són un signe d’alegria i un símbol de pertinença. Aquests menjars tenen una funció rememorativa i estableixen vincles claríssims amb tradicions evocades. Tenen una funció de preservació de la identitat del grup (Homobono, 2002). A l'esmorzar de Divendres Sant del 2011 vaig poder comprovar fins a quin punt l'organització de la trobada gastronòmica estava ritualitzada: els cuiners, els joves, les bromes, el mateix plat de cada any — sardines a la brasa amb mitja barra de mig del Forn Cristià-, les intervencions dels més grans, la intervenció dels més joves, etc. En destacaria una. Un armat, dels més grans a la colla, exhortava els joves a fer els canvis que volguessin en el futur, però que sobretot no perdessin la tradició de seure a taula tots plegats. Un desig que anava molt més enllà del plaer de menjar sardines a la brasa: es tracta de no perdre mai les eines que permeten la cohesió del grup, una aposta clara per a una vida llarga de l'entitat.

Ser armat és un refugi $i$ un espai on una colla d'homes gaudeixen. L'hedonisme és una de les seves raons de ser. Alhora, els armats donen sentit a una part de les seves vides. Cadascú, individualment, té moltes altres fonts de sentit, motivacions, com la família, la feina o altres entitats. Però aquesta és una d'important. I és una pertinença triada, no pas imposada. Aquesta és una de les característiques, precisament, de la modernitat avançada: la tradició ja no ve imposada, sinó que és triada. S'apel.la a la tradició com a font de legitimació però no estem davant d'una sociabilitat tradicional, sinó davant d'una suma de decisions individuals. El més important és el desig de pertinença i la sociabilitat (García, 2010). 
Altres estudis apunten precisament a conclusions semblants. És el cas de l'esmentat "Rituales colectivos, sociabilidad e identidad en Puente Genil (Córdoba)", on l'autor s'adona de la importància de l'ideal d'amistat i confraternització entre els membres. Aquest ideal és tan rellevant que es ritualitzen de manera contínua (Barrera, 1990). Aquest tipus de grups desenvolupen una important "ideologia de compromís", basada en una socialització dels nous membres, una pràctica de la fraternitat grupal i uns processos de simbolització interna que delimiten com sarticula i com s'organitza l'entitat.

La fraternitat, viure en una família àmplia dies festius, especials, compartir àpats, projectes, esborrar les barreres socials que existeixen a fora, l'experiència de la communitas, provoca benestar, plaer, comunió.

Un dels ritus habituals dels armats és l'homenatge als companys traspassats. Es tracta de recordar la persona durant la processó, en la presentació de l'opuscle, en l'organització d'una missa, en el sopar de gala o assistint al funeral. Aquest tipus d'acte reforça l'entitat. Els membres se senten orgullosos d'una associació que vetlla per ells, on l'harmonia i el sentit de germanor és un bé preuat.

\section{Creant trets d'identitat (locals i cristians)}

El vexillum era una mena d'estendard que emprava l'exèrcit romà. En comptes de ser horitzontal com una bandera, els vexillums tenien una caiguda vertical. Cada cohort dins la legió tenia la seva pròpia i servia per identificar-les i per reunir la tropa després de la batalla. El vexillum indicava de quina companyia era la tropa i quines eren les seves victòries. Els grups d'armats sempre en porten un. Qui el porta és l'abanderat o portavexillum. El vexillum torrenc duu dalt de tot la figura de la mà en comptes de làliga, que és el símbol de la legió romana. Porta inscrit el nom de l'entitat i del municipi.

L’any 2010 es van introduir els signums. Són dues figures noves inspirades en l'antic exèrcit romà. Cada signum encapçala una de les columnes de vuit soldats - una octiada —, tot i que originàriament, a l'exèrcit romà, acompanyava molts més soldats. Els signums de la Confraria de la Creu porten una mena d'estendard amb una torre al capdamunt. Aquesta torre simbolitza la Torre de la Vila, un dels llocs més emblemàtics del nucli antic del municipi i element que apareix a l'escut del municipi. Es va cercar un disseny que fos exclusiu, que nin- 
gú més tingués. Aquestes noves figures volen completar el conjunt que formen amb el vexillum. D'aquesta manera, amb els tres estendards al capdavant, es pot endevinar l'escut de la vila (dues torres i una mà estesa al mig).

Tot i que la Torre de la Vila no és un element d'origen romà - és medieval-, els armats no dubten a assumir aquest anacronisme com un símbol i fer-lo visible. Les activacions simbòliques que protagonitzen els armats són plenes d'aquestes paradoxes. D'una banda, se cerca una semblança científica (o cinematogràfica!) amb l'exèrcit romà $i$, de l'altra, s'inclouen elements que més aviat reforcen algun aspecte identitari local. L'equilibri de les paradoxes estètiques es troba en apropar-se a la imatge romana permetent elements que puguin identificar la colla com a torrenca.

Un so característic de la Setmana Santa torrenca d'abans era el de les matraques. Estaven instal.lades dalt del campanar i substituïen el so de les campanes el Dijous i el Divendres Sant perquè la litúrgia no permetia que sonessin fins Dissabte Sant. Una àvia vinculada a la parròquia recorda que les matraques eren habituals abans de la guerra i que després encara van sonar uns quants anys. Era una estructura de fusta rodona, com una bobina, d'uns 70 centímetres de diàmetre, amb un sistema de masses que picaven en girar una maneta. Per fer girar la maneta, que es trobava a una gran alçada, hi havia una corda que sestirava rítmicament. Fa uns anys, quan es van fer obres a la parròquia, es van despenjar per a restaurar-les. Ara es tornen a usar com a element tradicional, ajudant a diferenciar la localitat de la resta. És una iniciativa que lideren els armats. La voluntat de restaurar-les no és en va. Forma part de l'intent de recrear mites antics, exclusius, identitaris, del lloc.

La funció dels timbals és importantíssima. Marquen el ritme i el temps dels diferents passos. Anuncien al veïnat el seu pas pels carrers. Actualment, i des de fa molt temps, els passos són tres: el pas del Sastre, el pas militar i el pas d'armat. El pas del Sastre és una creació local, liderada per l'antic armat Antonio Sastre, i del qual se senten molt orgullosos.

Els armats també són els que han recuperat les caramelles. ${ }^{7}$ Surten de la porta falsa de l'església, després de l'ofici de Diumenge de Pasqua, i actuen pels carrers del nucli antic. Van vestits amb pantalons de pana, faixa, barretina i mocador al coll. Recuperar les caramelles té un significat especial. En primer lloc,

7. Les caramelles són cants populars que tenen lloc pels carrers el Diumenge Sant, quan representa que el fill del Déu dels cristians ha ressuscitat. 
amplia el nombre de dies de convivència intensiva i d'àpats per celebrar de la colla d'armats. En segon lloc, es recupera una tradició considerada molt important pels seus referents històrics i perquè molts familiars dels actuals cantaires hi havien actuat. De nou, la tradició. Recuperar aquell esperit de fraternitat, de poble d'abans. Aquesta lectura idíl.lica del passat és recreada al present amb joia. Per unes hores poden viure d'acord amb aquest passat idealitzat.

\section{El reclutament}

Els membres dels armats entrevistats van entrar a formar part de l'entitat a partir de la visita d'algun membre de la junta. L'entrada de nous membres és escalonada. Cal destacar la reproducció social a través de l'entrada de familiars (fills, néts, etc.) a la tropa. Aquesta modalitat de captació de nous membres ens remet a l'estudi esmentat més amunt de Josepa Cucó (1990) sobre l'associacionisme valencià. En aquest cas, també les vies de reclutament tenien lloc entre grups de parentiu, amistat $i$ veïnat.

Altres armats no tenen tradició familiar, però n'hi ha que l'han creada i els seus fills i parella s'han anat vinculant a la Setmana Santa. És el cas d'un dels informants. Ell és un element actiu de l'associacionisme torrenc. Actualment té un càrrec directiu dins l'entitat. Als armats troba les arrels que necessita per sentir-se del lloc.

Jo, que no tinc antecedents històrics familiars aquí, al poble, te n'enteres de moltes coses que després lligues coses que... i t'ho passes fenomenal. És molt bonic. I, possiblement, tota aquesta gent són per mi, una miqueta, els meus, tots els avantpassats que no tinc d'aquí al poble, no sé si mexplico. Sense serlos, parles d'aquell, parles de l'altre i són casi tiets o avis teus, casi, casi, no? Per dir-ho d'alguna manera, vull dir. Realment, reps una vivència històrica molt... que et fa ser més d'aquí, sense haver-ho sigut, d'alguna manera. (Membre dels armats.)

Es tracta d'una cerca premeditada, que té molt a veure amb els temps que vivim. Fer arrels, amb voluntat de sentir-se d'algun lloc. Diversos autors s'han fixat en aquesta paradoxa. El professor de la UAB Joan Subirats (2010) ho indica en aquests termes: "Más movilidad que nunca y más deseo de enraizamiento".

Una gran majoria dels seus membres pertanyen a més d'una entitat del municipi (geganters, seguici popular, Unió Deportiva, Coral Santa Rosalia, etc). 
És un fenomen que és percebut com a general entre els participants de la Setmana Santa:

Jo sempre he calculat unes quatre-centes persones, participants actives. Quatre-centes persones són... Que, a més, si miréssim, la majoria, la gran majoria d'aquestes persones, són actives en moltíssimes altres coses de la vila. Vull dir que realment no és allò que ho fan perquè no tenen res més a fer. Al contrari. Que ha fet un forat dintre el seu temps per poguer-se ficar doncs a... (Membre dels armats.)

El procés de revitalització festiva de caire popular no és un fenomen aillat. La recuperació de la vessant tradicional de la festa major del poble es produeix en paralllel a la revitalització dels armats i del conjunt de la Setmana Santa, és a dir, a partir de finals de la dècada del 1980 fins ara. De la mateixa manera, l'antropòleg Andrés Barrera atribuïa la vitalitat dels grups que feien la Setmana Santa a Puente Genil (Córdoba) precisament al fenomen generalitzat de revitalització festiva i localista.

Amb aquesta voluntat d'arrelar, de ser autèntics, de desmarcar-se de la varietat d'habitants que té el municipi, de l'heterogeneïtat, es remarca en els seus relats que ells formen part del nucli dur del poble, aquell originari grup de famílies que viuen, treballen i se senten del poble.

Total, som un poble de 15.000 habitants i podríem dir-ho, sense caure en l'error, que forma part dels “3.000 habitants". No sé si mexplico el que vull dir. Si tu mires noms i cognoms de qui hi van i hi deixen d'anar, poca gent hi ha allà que siguin nousvinguts. I n'hi ha, n'hi ha molts, i com més en vinguin, millor. Però la majoria, el cos central, el tronc d'aquest 5 de 7 és gent de sempre, del poble, de tota la vida, de... Els passos són els que ja hi havia, vull dir, no s'ha fet tanta innovació. Sí que les vestes és roba nova, però tot el que hi ha i tot el sentiment és molt antic. (Membre dels armats.)

El poble és el motiu, el sentit de ser, la mare, el tot, allà on creix la família, on es balla, es riu, es plora i s'enterren els morts. Per tot plegat, si convé fer un "esforç" pel poble, es fa. Per ells, treballar pels armats és treballar pel poble. Esforçar-se, sacrificar-se pels armats és sacrificar-se pel poble. Aquest poble és una "comunitat imaginada". No pas perquè no es conegui a tots i cadascun dels seus habitants, sinó perquè no respon a la realitat complexa i heterogènia. Aquesta realitat no és sentida com a pròpia. Per ells, el "poble" és una comuni- 
tat arrelada amb la tradició, on les famílies es coneixen pels noms de les cases encara que visquin en xalets allunyats del nucli i encara que en aquestes cases hi visquin de relloguer famílies nombroses de magrebins. En aquest imaginari, l'Església ocupa un espai central, és un punt de trobada i de lleure i el calendari festiu —d'arrel cristiana - continua marcant els temps anuals quasi de manera circular.

I en el mateix sentit, pels armats, tot i ser un espai on passar-ho bé, si convé un sacrifici per al col.lectiu, es fa. Si convé pagar més, cadascú, pel sopar de gala per poder convidar els homenatjats, es fa. Els assajos són dissabte al vespre! El sacrifici demana no faltar mai de manera no justificada. Per la resta dels anys no es podrà marxar de vacances durant aquells dies.

Però precisament la Junta que som ara i la Junta que va fer el canvi, diguéssim, jo penso que una de les característiques que teníem, a part que érem joves i tot lo que tu vulguis, era que érem tots emprenedors. Tots teníem ganes i no ens importava el risc d'haver d'apostar per algo. (Membre dels armats.)

Hem de tenir en compte que històricament els actes de la Setmana Santa s'havien pagat a través de donatius més o menys anònims. Una informant de 90 anys m'explica que passava per les cases a recollir els donatius i que en algunes cases eren rebudes amb paraules despectives contra l'Església: "Digueu al senyor rector que els sants no mengen!"

Els membres dels armats viuen la Setmana Santa com un element més del calendari festiu vinculat a les celebracions d'arrel cristiana. De fet, per aquest sector de persones els actes de festa major també tenen una significació religiosa. Molts són els que entren a l'església a fer l'ofrena al Quadre de Santa Rosalia, escolten l'ofertori, els que participen en la processó de la Festa del Quadre, etc. ${ }^{8}$ Cal recordar la funció de les festes organitzades per les comunitats, que sempre tenen una funció de crear cohesió del grup i sentiment de pertinença (Ariño, 1998).

Ara que estem, una mica, amb làliga, la festa major i tot això, pues no és tant, no necessites tant, no es fan tantes reunions, però... Les coses és millor viureles des de dintre que ser espectador. T'ho passes millor. (Membre dels armats.)

8. Són els actes de caire religiós més importants que formen part de la Festa del Quadre, el 15 de juliol, i Santa Rosalia, el 4 de setembre. 


\section{Conclusions}

Sens dubte, el seu origen i el seu sentit és profundament religiós. Però també estem davant d'un fenomen de cultura popular perquè sassigna a l'espai públic un paper central i perquè les persones que utilitzen aquest espai com a vianants se l'apropien en aquell moment per convertir-lo en suport d'una expressió compartida. De manera efímera, respectant un calendari cíclic tradicional, un gran públic envaeix el carrer per conviure i cooperar. Els participants, alhora espectadors i actors, trenquen la definició estàtica dels carrers. No només són vies de pas entre construccions. Els carrers i les places són el marc de relació d'una comunitat, accessibles, versàtils i simbòlics (Delgado et al., 2005).

Els diferents passos que participen no paren de créixer. Un dels informants parla d'atractiu turístic, folklòric i tradicional gràcies a l'ordre, el gust estètic i la dignitat amb què es posa en escena la processó.

Actualment, la Confraria de la Creu compta amb més de 150 socis i sòcies. Editen un opuscle anual amb més de 80 pàgines, amb una vintena d'anunciants i coordinat per la Junta de la Confraria. Reben el suport de l'Ajuntament, el Consorci dels Municipis Turístics del Baix Gaià, la Diputació de Tarragona, el Patronat Municipal de Cultura, la parròquia de Sant Pere Apòstol, el Patronat Municipal de Turisme i l'Obra Social de Caixa Tarragona. La Confraria coordina la Setmana Santa i ha sabut rellançar el conjunt dels seus actes fins al punt d'esdevenir un fenomen de participació i un atractiu per als visitants. De fet, la Confraria ha sabut vendre a les administracions el seu potencial turístic per aconseguir fons econòmics per ampliar les seves activitats, invertir més en l'estètica del seu espectacle, crear elements diferenciadors i identitaris.

Si Hannerz (1998) parla que les respostes a la globalització se situen entre el cosmopolitisme i el localisme, podríem situar el nostre objecte d'estudi entre les respostes localistes. La tendència a reforçar les pràctiques rituals, a crear-ne de noves que reforcen les antigues i a projectar-se cap al futur amb aquests paràmetres ens parla precisament d'això. Malgrat el localisme, els beneficis de la globalització són acceptats (les noves tecnologies, per exemple), però sempre en benefici d'aquest localisme. Es tracta d'un localisme que combina creences religioses, tradicions heretades i recreades, representacions dramàtiques, àpats i diversos elements de plaer hedonista, tot sota la protecció d'una jerarquia i un poder collectivament acceptat. Identitats fortes en temps líquids. Els armats, 
com a col-lectiu, donen sentit a les vides dels seus membres, fins i tot als no creients, en un moment que, com deia Berger (1997), les societats modernes pateixen crisis latents de sentit. Els armats, com a institució intermèdia, contribueixen a la negociació i a l’objectivació social del sentit. Els seus membres no se senten "como completos extraños en el mundo moderno".

Davant les presses, les identitats líquides i múltiples, els armats ofereixen aixopluc a una colla d'homes, ni que sigui per uns dies l'any.

Els armats empren la tradició per legitimar la seva postura. Per tant, estem davant d'una entitat ben moderna $i$ inserida en les dinàmiques provocades per la globalització: Aprofiten les noves tecnologies per a un ús intern (organització) i extern (difusió), i reaccionen contra els efectes que consideren negatius (la pèrdua d'identitat territorial, per exemple).

Els armats fan un gran esforç per crear localitat, encara que, com hem vist, és només una part d'una realitat més complexa. El territori és cada cop menys important per definir identitats. En canvi, per als armats, el poble, el país i les seves tradicions són el seu marc de referència. S'identifiquen amb aquest territori d'una manera redundant. La reivindicació d'aquesta identitat ha esdevingut una de les seves raons de ser.

L'associació analitzada és emprada per diferents persones per arrelar al municipi on ha decidit anar a viure. Però l'entrada a l'entitat de nous membres és força lenta. Entrar a formar part de la troba significa normalment que algun membre ha plegat i això no acostuma a passar. Els armats ho són durant molts anys. Malgrat que els seus estatuts no marquen gaires dificultats per entrar a l'entitat, la realitat és que la manera de captar nous socis és a través de contactes d'amistat i de vincles familiars. Qui aconsegueix entrar a l'entitat sí que gaudeix d'una visibilitat en el municipi i d'una bona plataforma per participar en altres iniciatives ciutadanes. La seva vocació és la de ser un baluard de la tradició (recreada) i la identitat local (imaginada).

Hi ha armats en ple segle xxi i continuarà havent-n'hi durant molts anys. La seva presència a molts municipis és notòria i esperada. Les persones que hi participen ho fan amb entusiasme i senten una barreja de plaer i d'obligació que els fa no defallir. Motius? Els armats són un espai que ofereix als seus membres una identitat forta de grup, que serveix per donar sentit a les vides dels seus membres i sensació de protecció davant dels canvis accelerats del seu entorn. Aquesta identitat de grup s'aconsegueix, entre d'altres, amb la cerca premedita- 
da de trets que els diferencien d'altres colles i amb l'establiment d'uns ritus i una estructura perfectament definida.

Els armats juguen un paper important en la creació de la identitat local. Es tracta d'una relació simbiòtica en què els armats aprofiten elements locals per bastir la seva identitat i els seus símbols i en què la localitat explota els efectes de la tasca dels armats per reivindicar la seva especificitat. Es reivindica el lloc no des del punt de vista d'aquells que han quedat al marge de la globalització. $\mathrm{Al}$ contrari, la localitat cerca trets distintius per atreure fluxos, en aquest cas turístics. Aquesta relació simbiòtica no és a l'abast de tothom. Calen bones relacions amb el poder, calen mitjans econòmics, subvencions i contactes. Els que queden al marge del circuit no poden negociar. Associar-se serà una primera fase d'apoderament però, finalment, serà el poder polític i econòmic qui triarà els agraciats per al benefici, precisament, dels seus projectes.

Podem concloure, d'altra banda, que l'anàlisi de l'associacionisme pot ser un bon marc per conèixer i analitzar els canvis produïts per la globalització. En efecte, l'associacionisme és un espai de referència ben delimitat on l'embat de la globalització hi deixa empremta. Pel factor humà, pel contacte directe, per la vivesa i per la importància de l'associacionisme en la cohesió social, cal tenir present aquest objecte d'estudi. També cal tenir present l'associacionisme transnacional i els moviments socials, com a canalitzadors de noves identitats deslligades dels territoris delimitats.

\section{Bibliografia}

Appadurai, A. (2001). La modernidad desbordada. Dimensiones culturales de la globalización. Mèxic: Fondo de Cultura Económica.

Ariño, A. (1998). "Festa i ritual: dos conceptes bàsics". Revista d'Etnologia de Catalunya, núm. 13, p. 8-17.

Augé, M. (2008). Los no lugares. Espacios del anonimato. Una antropología de la sobremodernidad. Barcelona: Gedisa.

Barrera, A. (1990). "Rituales colectivos, sociabilidad i identidad en Puente Genil (Córdova)”. Dins Josepa Cucó i Joan Josep Pujadas. Identidades colectivas. València: Generalitat Valenciana, p. 187-198.

BARTh, F. (1976). Los grupos étnicos y sus fronteras. Mèxic: Fondo de Cultura Económica. 
Bauman, Z. (2003). La globalización. Consecuencias humanas. Mèxic DF: Fondo de Cultura Económica.

Berger, P. L.; Luckmann, T. (1997). Modernidad, pluralismo y crisis de sentido. La orientación del hombre moderno. Barcelona: Paidós.

Cantón, M. (2001). La razón hechizada. Teorías antropológicas de la religión. Barcelona: Ariel Antropología, 2001.

Castells, M. (2005). "La importancia de la identidad", La Vanguardia (05XI-2005), p. 29.

Cucó, J. (1990). "Asociaciones y cuadrillas: Un primer avance al análisis de la sociabilidad formal valenciana". Dins J. Cucó i J. J. Pujadas [coord.]. Identidades colectivas. Etnicidad y sociabilidad en la Peninsula Ibérica. València: Generalitat Valenciana, p. 219-231.

- (2004). Antropología urbana. Barcelona: Ariel.

Delgado, M.; Feixa, C.; Pablo, J.; Soler, J.; Ventosa, S. (2005)."Lespai i l'escenografia". Dins Joan Soler [dir.]. Tradicionari. Vol. IV: "La festa”. Barcelona: Enciclopèdia Catalana / Generalitat de Catalunya, p. 28-64.

Durkheim, É. (2003). Las formas elementales de la vida religiosa. Madrid: Alianza Editorial.

Frigolé, J. (2006). “Globalización y transformaciones sociales, económicas y culturales en áreas de montaña”. Dins Joan Frigolé, i Xavier Roigé [coord.]. Globalización y localidad. Perspectiva etnogràfica. Barcelona: UB.

GArcía, P. (2010). Tradición en la modernidad avanzada: la Semana Santa Marinera de Valencia. València: Museu Valencià d'Etnologia / Diputació de València.

García Canclini, N. (1990). Culturas hibridas. Estrategias para entrar y salir de la modernidad. Mèxic: Grijalbo.

Geertz, C. (1990). La interpretación de las culturas. Barcelona: Gedisa.

Giddens, A. (1997). Modernidad e identidad del yo. El yo y la sociedad en la época contemporánea. Barcelona: Ediciones Península.

- (1998). Capitalismo y la moderna teoría social. Barcelona: Idea Books.

Hannerz, U. (1998). Conexiones transnacionales. Cultura, gente, lugares. Madrid: Cátedra / Universitat de València.

Номовоnо, J. I. (2002). "Adaptando tradiciones y reconstruyendo identidades. La comensalidad festiva en el ámbito pesquero vasco-cantábrico”. Dins 
Mabel Gracia [coord.]. Somos lo que comemos. Estudios de alimentación y cultura en España. Barcelona: Ariel.

Lacroix, M. (2005). El culte a l'emoció. Atrapats en un món d'emocions sense sentiments. Barcelona: Edicions La Campana.

Lévi-Strauss, C. (1979). Antropología estructural. Mito, sociedad, bumanidades. Madrid: Siglo XXI.

Plata, F. (I989). "Asociacionismo masculino y rituales festivos en la campiña cordobesa”. Dins Carlos Álvarez, María Jesús Buxó i Salvador Rodríguez [coord.]. La religiosidad popular. Vol. III: Hermandades, romerias y santuarios. Barcelona: Anthropos, p. 544-556.

Prat, J.; Moreno, J. (2007). “La nebulosa místico-esotèrica”. Dins Tradicionari. Vol. VIII. Barcelona: Editorial Enciclopèdia Catalana, p. 278-289.

Rodríguez, X. S. (2004) “'Las paradojas de la negociación de una identidad nacional gallega”. Quaderns, núm. 20. Institut Català d'Antropologia, p. 81103.

Subirats, J. (2010). “Que todo sea como antes”. El País (04-IX-2010), p. 2 (suplement de Catalunya).

Turner, V. W. (1988). El proceso ritual. Estructura y antiestructura. Madrid: Taurus.

Vallverdú, J. (2008). Antropología simbólica. Teoría y etnografía sobre religión, simbolismo y ritual. Barcelona: UOC.

Weber, M. (1964). Economía y sociedad. Esbozo de sociología comprensiva. Mèxic: Fondo de Cultura Económica. 